\title{
Impulsivity traits and addiction-related behaviors in youth
}

\author{
KRISTINE RØMER THOMSEN ${ }^{1 *}$, METTE BUHL CALLESEN ${ }^{1}$, MORTEN HESSE ${ }^{1}$, TIMO LEHMANN KVAMME${ }^{1}$, \\ MICHAEL MULBJERG PEDERSEN ${ }^{1}$, MADS UFFE PEDERSEN ${ }^{1}$ and VALERIE VOON ${ }^{2}$ \\ ${ }^{1}$ Department of Psychology and Behavioural Sciences, Centre for Alcohol and Drug Research, Aarhus University, Aarhus, Denmark \\ ${ }^{2}$ Department of Psychiatry, University of Cambridge, Addenbrookes Hospital, Cambridge, UK
}

(Received: November 25, 2017; revised manuscript received: January 28, 2018; second revised manuscript received: February 22, 2018; accepted: March 11, 2018)

\begin{abstract}
Background and aims: Impulsivity is a risk factor for addictive behaviors. The UPPS-P impulsivity model has been associated with substance addiction and gambling disorder, but its role in other non-substance addiction-related behaviors is less understood. We sought to examine associations between UPPS-P impulsivity traits and indicators of multiple substance and non-substance addiction-related behaviors in youth with varying involvement in these behaviors. Methods: Participants ( $N=109$, aged 16-26 years, 69\% males) were selected from a national survey based on their level of externalizing problems to achieve a broad distribution of involvement in addiction-related behaviors. Participants completed the UPPS-P Questionnaire and standardized questionnaires assessing problematic use of substances (alcohol, cannabis, and other drugs) and non-substances (Internet gaming, pornography, and food). Regression analyses were used to assess associations between impulsivity traits and indicators of addiction-related behaviors. Results: The UPPS-P model was positively associated with indicators of all addiction-related behaviors except problematic Internet gaming. In the fully adjusted models, sensation seeking and lack of perseverance were associated with problematic use of alcohol, urgency was associated with problematic use of cannabis, and lack of perseverance was associated with problematic use of other drugs than cannabis. Furthermore, urgency and lack of perseverance were associated with binge eating and lack of perseverance was associated with problematic use of pornography. Discussion and conclusions: We emphasize the role of trait impulsivity across multiple addictionrelated behaviors. Our findings in at-risk youth highlight urgency and lack of perseverance as potential predictors for the development of addictions and as potential preventative therapeutic targets.
\end{abstract}

Keywords: impulsivity, substance use, binge eating, pornography, Internet gaming, addiction

\section{INTRODUCTION}

\section{Impulsivity and UPPS-P}

Impulsivity is broadly defined as the tendency toward rapid, poorly considered, and disinhibited decisions and actions, despite negative consequences. Impulsivity is increasingly conceptualized as multidimensional (Evenden, 1999; Sperry, Lynam, Walsh, Horton, \& Kwapil, 2016), and the subcomponents are heterogeneous in nature and associated with discrete but overlapping neural substrates (Dalley, Everitt, \& Robbins, 2011).

Impulsivity can be measured using self-report, such as the UPPS-P Impulsive Behavior Scale (Lynam, Smith, Whiteside, \& Cyders, 2006), or by computerized behavioral tasks measuring subcomponents, such as premature responding (4-Choice Serial Response Time Task; Voon, Irvine, et al., 2014) and response inhibition (e.g., Go/Nogo Task; Garavan, Ross, \& Stein, 1999). Recent meta-analytic evidence suggests that self-report and behavioral measures of impulsivity share less than 5\% variance (Cyders \& Coskunpinar, 2011) suggesting both make unique contributions. Self-report measures are useful for assessing an individual's general tendencies or traits and are superior in ecological validity, whereas behavioral tasks provide a "snapshot" of what the individual actually does, and may be less vulnerable to face-validity problems (Cyders \& Coskunpinar, 2011; Sperry et al., 2016).

In this study, we focus on the UPPS-P model, which captures the multidimensional nature of impulsivity. The original UPPS model posits four separate, albeit related, impulsive personality traits (Whiteside \& Lynam, 2001): negative urgency, the tendency to act rashly in intense negative emotional states; (lack of) premeditation, the tendency to act without forethought and planning; (lack of) perseverance, the tendency not to finish tasks; and sensation seeking, the tendency to seek sensory pleasure and excitement. The model has shown good discriminant and convergent validity (Smith, Fischer, Cyders, Annus, \& Spillane, 2007), and has proven

\footnotetext{
* Corresponding author: Kristine Rømer Thomsen; Department of Psychology and Behavioural Sciences, Centre for Alcohol and Drug Research, Aarhus University, Bartholins Allé 10, Building 1322, Aarhus C 8000, Denmark; Phone: +45 871654 47; Fax: +45 871644 20; E-mail: krt.crf@psy.au.dk
}

This is an open-access article distributed under the terms of the Creative Commons Attribution-NonCommercial 4.0 International License, which permits unrestricted use, distribution, and reproduction in any medium for non-commercial purposes, provided the original author and source are credited, a link to the CC License is provided, and changes - if any - are indicated. 
useful in characterizing disorders involving impulsive behavior, such as substance use disorders (SUDs) (VerdejoGarcia, Bechara, Recknor, \& Perez-Garcia, 2007; Whiteside \& Lynam, 2003). The new version, UPPS-P, includes positive urgency (the tendency to act rashly in intense positive emotional states) (Lynam et al., 2006). The first validation studies indicated that the fifth trait can be measured in a contentvalid, reliable way that is different to the other facets (Cyders et al., 2007; Verdejo-Garcia, Lozano, Moya, Alcazar, \& PerezGarcia, 2010). However, the separability of the urgency scales has later been questioned (Berg, Latzman, Bliwise, \& Lilienfeld, 2015).

\section{Role of impulsivity in addictive behaviors}

Impulsivity is commonly impaired dimensionally across SUD (Dalley et al., 2011; Voon \& Dalley, 2016), and subcomponents have been shown to be a risk factor in the development of problematic substance use and SUD (Dalley et al., 2007; Ersche et al., 2012; Kaiser, Bonsu, Charnigo, Milich, \& Lynam, 2016).

Studying these relationships during adolescence and young adulthood is of particular importance, because this is when substance use is usually initiated and impulsive behavior is elevated. According to meta-analyses of adolescents and young adults, positive urgency and negative urgency show the strongest association with problematic alcohol use (Coskunpinar, Dir, \& Cyders, 2013; Stautz \& Cooper, 2013). Another meta-analysis of adolescents found medium associations between negative cannabis consequences and sensation seeking, lack of premeditation, and positive urgency (VanderVeen, Hershberger, \& Cyders, 2016). Studies examining problematic use of illegal drugs, such as cocaine, also point to a role of urgency (AlbeinUrios, Martinez-Gonzalez, Lozano, Clark, \& VerdejoGarcia, 2012; Fernandez-Serrano, Perales, Moreno-Lopez, Perez-Garcia, \& Verdejo-Garcia, 2012; Torres et al., 2013); however, so far, these relationships have only been tested in adult, clinical samples. Taken together, urgency has been most consistently associated with problematic substance use among youth. Theories on emotion regulation provide possible explanations for this link by suggesting that individuals who experience problems in regulating negative emotions may indulge immediate impulses in an attempt to downregulate intense negative emotions (despite longterm negative consequences), thereby creating a risk for addictive behaviors (Tice, Bratslavsky, \& Baumeister, 2001). According to the Acquired Preparedness Model (Settles, Cyders, \& Smith, 2010), positive urgency predisposes individuals to acquire expectations that substances have positive effects, whereas negative urgency predisposes individuals to use substances to cope with negative emotions, both of which increase use.

In addition to SUD, impulsivity has been shown to play an important role in non-substance-related addictive disorders. The fifth edition of Diagnostic and Statistical Manual of Mental Disorders (DSM-5; American Psychiatric Association, 2013) marked an important change in the diagnosis of addictive behaviors by including nonsubstance-related addictive disorders, often labeled as behavioral addictions. Based on decades of work, gambling disorder was accepted as the first behavioral addiction, and there is an ongoing debate regarding potential classification of other behaviors in DSM-6 and the forthcoming ICD-11. Problematic use of Internet gaming, pornography, and binge eating are often conceptualized as behavioral addictions due to emerging evidence suggesting some overlap in underlying psychological and neurobiological mechanisms (Amianto, Ottone, Daga, \& Fassino, 2015; Gola et al., 2017; Kraus, Voon, \& Potenza, 2016; Kuss, Griffiths, \& Pontes, 2017; Petry, Rehbein, Ko, \& O’Brien, 2015). However, more research is needed and critical concerns have been raised, for example, regarding potential over-pathologizing of elevated desires (Billieux, Schimmenti, Khazaal, Maurage, \& Heeren, 2015). Other critical concerns are the lack of consensus regarding definitions and diagnostic criteria, and the fact that the diagnostic criteria have been directly adapted from SUD (Billieux et al., 2015; Kardefelt-Winther et al., 2017).

Subcomponents of impulsivity have been shown to be involved in gambling disorder, including response inhibition (Rømer Thomsen et al., 2013) and trait impulsivity (Billieux et al., 2012; Savvidou et al., 2017), but overall, we lack research on the role of trait impulsivity in other types of addiction-related behaviors. Studies of young and adult samples point to a role of negative urgency and positive urgency in gambling disorder (Billieux et al., 2012; Canale, Scacchi, \& Griffiths, 2016; Fischer \& Smith, 2008; GrallBronnec et al., 2012; Michalczuk, Bowden-Jones, VerdejoGarcia, \& Clark, 2011; Savvidou et al., 2017). A number of studies indicate that urgency, particularly negative urgency, is implicated in binge eating in adult/young adult clinical and non-clinical samples (Claes et al., 2015; Kelly, Cotter, \& Mazzeo, 2014; Mikheeva \& Tragesser, 2016; Murphy, Stojek, \& MacKillop, 2014; VanderBroek-Stice, Stojek, Beach, vanDellen, \& MacKillop, 2017), and some studies show associations with lack of perseverance (Claes et al., 2015; Murphy et al., 2014; VanderBroek-Stice et al., 2017). The literature on the UPPS-P model in compulsive use of Internet gaming and pornography is limited. Two studies of young adults failed to find consistent associations between the UPPS-P and signs of excessive online gaming (Irvine et al., 2013; Nuyens et al., 2016). In a recent study of young adults, UPPS-P scores did not discriminate between healthy gamers and gamers endorsing DSM-5 Internet gaming disorder (Deleuze et al., 2017). A recent study of young adults/adults reported a positive association between negative urgency and addictive use of online sexual activities (Wery, Deleuze, Canale, \& Billieux, 2018), and an imaging study found higher rates of impulsivity in young adults with compulsive sexual behavior compared with individuals without it (Voon, Mole, et al., 2014), but did not report subscales.

In sum, while the model's role is well-characterized in adolescent samples with problematic alcohol and cannabis use, we have limited knowledge of its role in non-substance addiction-related behaviors among youth, particularly problematic Internet gaming and pornography use.

Here, we examined associations between impulsivity traits and indicators of substance (alcohol, cannabis, and other drugs) and non-substance (Internet gaming, pornography, and eating) addiction-related behaviors among youth with varying involvement in these behaviors. Based on 
empirical findings, and theories of emotion regulation, we hypothesized that negative urgency and positive urgency would be positively associated with problematic substance use. In line with the recent conceptualizations of problematic use of pornography and binge eating as behavioral addictions, and the limited literature available, we hypothesized that negative urgency and positive urgency would be positively associated with these behaviors. Due to recent null findings, we hypothesized that problematic use of Internet gaming would not be associated with UPPS-P model.

\section{METHODS}

\section{Participants and procedure}

The data included in this study are part of a larger study examining risk factors for addictive behaviors. To obtain a sample with a broad distribution of addiction-related behaviors, youth with varying levels of externalizing behavior problems (problem behaviors directed outward toward others) and low levels of internalizing behavior problems (problem behaviors directed inward toward oneself) were included. Externalizing and internalizing problems were measured with YouthMap12, a 12-item questionnaire with six items identifying externalizing problems (EP6) and internalizing problems (IP6; Pedersen, Rømer Thomsen, Pedersen, \& Hesse, 2017). Externalizing behavior problems have been consistently shown to increase risk of problematic substance use among both genders (Fischer, Najman, Williams, \& Clavarino, 2012; Heron et al., 2013; Miettunen et al., 2014), and EP6 has been strongly associated with problematic substance use among youth across Nordic countries (Pedersen et al., in press; Pedersen et al., 2017). In contrast, studies point to no associations with internalizing problems (Griffith-Lendering, Huijbregts, Mooijaart, Vollebergh, \& Swaab, 2011; Miettunen et al., 2014), which may act as protective factors (Colder et al., 2013; Edwards et al., 2014).

Participants were recruited from a nationally representative survey with 3,064 randomly selected 15- to 25-year-old Danes [response rate 63\%; males $51.1 \%$; student $79.1 \%$; employed 15.7\% (see Pedersen, Frederiksen, \& Pedersen, 2015)] conducted in 2014 by Statistics Denmark. Out of the 205 who received a postal letter, 78 were included in the study. To increase sample size, additional participants were recruited through advertisements. In total, we included 109 (aged 16-26 years) with varying levels of EP6: no externalizing problems $(n=34)$, minimal externalizing problems $(n=19)$, moderate externalizing problems $(n=25)$, severe externalizing problems $(n=31)$, and minimal $(0-2)$ internalizing problems in all groups (Figure 1).

Participants were included if they had no current major psychiatric disorder assessed with the Mini International Neuropsychiatric Inventory (Lecrubier et al., 1997) and did not receive medication affecting the brain. Participants were instructed to abstain from substances (other than tobacco) at least $24 \mathrm{hr}$ prior to their participation.

The study was conducted at CFIN/MINDLab facilities at Aarhus University, Denmark. On the day of testing, participants completed standardized questionnaires on a computer (not counterbalanced, lasting about $30 \mathrm{~min}$ ), and a research assistant was present to answer any arising questions.

\section{Measures}

Impulsivity traits were measured using the UPPS-P Impulsive Behavior Scale (Cyders et al., 2007; Lynam et al., 2006), a 59-item questionnaire assessing impulsivity traits: negative urgency, (lack of) premeditation, (lack of) perseverance, sensation seeking, and positive urgency. Due to a high degree of association between the urgency scales $(r=.71)$, we combined them in one urgency variable (i.e., the tendency to act rashly in reaction to intense emotions), which was used in all subsequent analyses. This is in line with recent studies (e.g., VanderBroek-Stice et al., 2017) and findings from a meta-analysis of the model across psychopathologies, which found very similar correlational patterns with these subscales, thereby questioning their distinctiveness (Berg et al., 2015).

Problematic alcohol use was measured using the Alcohol Use Disorder Identification Test (AUDIT; Saunders, Aasland, Babor, Delafuente, \& Grant, 1993), a 10-item questionnaire developed as a screening instrument for hazardous and harmful alcohol consumption. The AUDIT is a valid measure of harmful use/abuse/dependence of alcohol and demonstrates good sensitivity and specificity (Meneses-Gaya, Zuardi, Loureiro, \& Crippa, 2009).

Problematic cannabis use was measured using the Cannabis Use Disorder Identification Test - Revised (CUDIT-R), a brief 8-item version of the CUDIT (Adamson \& Sellman, 2003), which has equivalent or superior psychometric properties (Adamson et al., 2010).

Problematic use of drugs (other than cannabis) was measured using the Drug Use Disorder Identification Test (DUDIT; Berman, Bergman, Palmstierna, \& Schlyter, 2005), a psychometrically sound (Berman et al., 2005; Hildebrand, 2015; Voluse et al., 2012) 11-item questionnaire assessing patterns of drug use and drug-related problems.

Problematic Internet gaming behavior was measured using the Internet Gaming Disorder Scale - Short Format (IGDS9-SF; Pontes \& Griffiths, 2015), a recently developed 9-item questionnaire adapted from the nine criteria that define Internet gaming disorder according to DSM-5. The IGDS9-SF is considered a valid and reliable measure of Internet gaming disorder (Pontes \& Griffiths, 2015).

Problematic pornography use was measured using the Pornography Craving Questionnaire (PCQ; Kraus \& Rosenberg, 2014), a recently developed 12-item questionnaire assessing aspects of current craving for pornography, including desire, intention, physiological arousal, and anticipated difficulty in restraining use, and with good internal consistency and reliability (Kraus \& Rosenberg, 2014).

Problematic eating, or binge eating, was measured using the Binge Eating Scale (BES; Gormally, Black, Daston, \& Rardin, 1982), a 16-item questionnaire assessing behavioral, emotional, and cognitive symptoms associated with binge eating, with high sensitivity and specificity for identifying individuals with binge eating behavior (Duarte, PintoGouveia, \& Ferreira, 2015). 
Nationally representative survey in 2014 conducted by Statistics Denmark with 3,064 randomly selected Danes between 15-25 years of age, covering substance use and related problems, incl. externalizing problems (EP6) and internalizing problems (IP6).

Based on EP6 and IP6 scores, 205 youths were selected and received a postal letter in Fall 2015 with an invitation to take part in a large study examining risk factors for addictive behaviours (including imaging).

Out of the 205, 146 responded positively and agreed to be contacted to hear more about the study (59 declined or did not respond to the letter).

Out of the 146, 78 were interested in taking part and fulfilled inclusion criteria, and hence were included (64 declined after more information or did not fulfill inclusion criteria).
We had expected a larger proportion of the 205 to be interested and eligible. In order to account for this and increase sample size, we advertised the study. 39 participants responded to these advertisements.

Out of the 39, 31 were interested in taking part and fulfilled inclusion criteria, and hence were included ( 8 declined after more information or did not fulfill inclusion criteria).

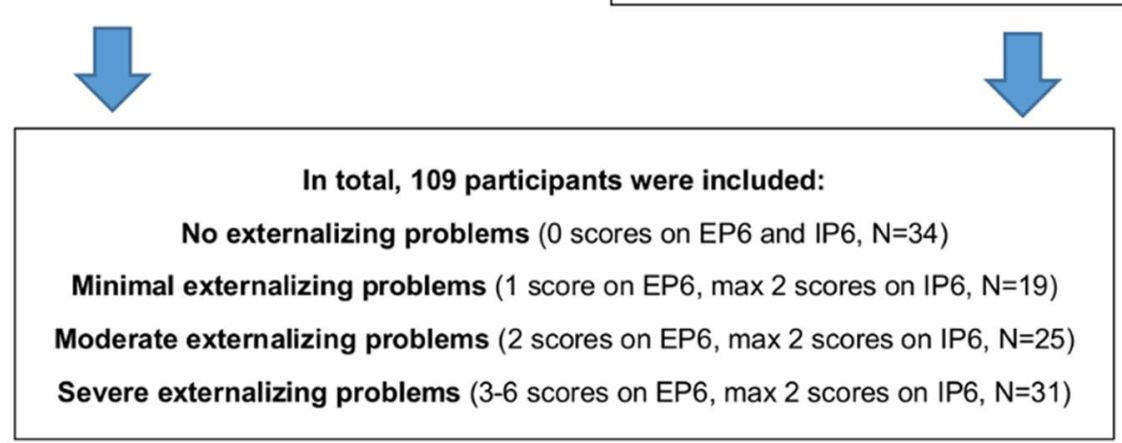

Figure 1. Flowchart of the inclusion process. Participants were selected based on their level of self-reported externalizing behavior problems (EP6, ranging from 0 to 6) and internalizing behavior problems (IP6, ranging from 0 to 6 ), to obtain a sample with a broad involvement in addiction-related behaviors. Participants were recruited from a nationally representative survey $(N=3,064$, aged 15-25 years) conducted in 2014 by Statistics Denmark. To increase sample size, a small group of participants were recruited through advertisements. In total, 109 adolescents and young adults with varying levels of externalizing problems and varying levels of use were included in the study

The AUDIT, CUDIT-R, and DUDIT were available in Danish, and remaining questionnaires were translated from English to Danish by two Danish researchers with proficient English language abilities.

We included the sociodemographic variables, gender, age, and completed years of formal education. Gender and age have been related to substance use and SUD, for example, with use increasing with age from early to late adolescence and with more use among males (Young et al., 2002), and basic education has been shown to be an excellent proxy for socioeconomic risk for drug use disorders in Scandinavia (Gauffin, Vinnerljung, Fridell, Hesse, \& Hjern, 2013).

\section{Statistical analysis}

Regression analyses were performed to assess associations between impulsivity traits and addiction-related outcomes. Variance inflation factors (Table 1) were far below 4.0 and 
Table 1. Sample characteristics

\begin{tabular}{|c|c|c|c|c|c|}
\hline & Mean $(S D)$ & Min-max & Possible range & Cronbach's $\alpha$ & Variance inflation factor \\
\hline \multicolumn{6}{|l|}{ Demographic } \\
\hline Gender (male) & $68.8 \%$ & & & & 1.19 \\
\hline Age & $21.7(2.7)$ & $15.8-26.7$ & & & 1.84 \\
\hline Years of education & $13.4(1.9)$ & 9-18 & & & 1.86 \\
\hline \multicolumn{6}{|l|}{ Impulsivity } \\
\hline Urgency $^{\mathrm{a}}$ & 44.9 (11.7) & $26-75$ & $26-104$ & .92 & 1.46 \\
\hline (Lack of) Premeditation & $23.1(6.1)$ & $12-42$ & $11-44$ & .86 & 1.61 \\
\hline (Lack of) Perseverance & $17.7(4.5)$ & $10-30$ & $10-40$ & .80 & 1.45 \\
\hline Sensation seeking & $32.8(6.4)$ & $19-46$ & $12-48$ & .82 & 1.40 \\
\hline \multicolumn{6}{|c|}{ Indicators of substance-related addictive behaviors } \\
\hline AUDIT & $8.8(5.9)$ & $0-29$ & $0-40$ & .78 & \\
\hline CUDIT-R & $3.1(5.5)$ & $0-25$ & $0-32$ & .86 & \\
\hline DUDIT & $1.9(4.7)$ & $0-23$ & $0-44$ & .86 & \\
\hline \multicolumn{6}{|c|}{ Indicators of non-substance addiction-related behaviors } \\
\hline BES & $7.3(4.9)$ & $0-21$ & $0-46$ & .78 & \\
\hline PCQ & $17.2(14.5)$ & $0-53$ & $12-84$ & .83 & \\
\hline IGDS9-SF & $9.7(9.2)$ & $0-45$ & $9-45$ & .91 & \\
\hline
\end{tabular}

Note. AUDIT: Alcohol Use Disorder Identification Test; CUDIT-R: Cannabis Use disorders Identification Test - Revised; DUDIT: Drug Use Disorder Identification Test; BES: Binge Eating Scale; PCQ: Pornography Craving Questionnaire; IGDS9-SF: Internet Gaming Disorder Short Format; $S D$ : standard deviation.

${ }^{a}$ Due to a high degree of association between the positive and negative urgency scales, these scales were combined into one urgency variable.

none of the correlations were above 0.8 (Table 2), indicating that multicollinearity was not a problem (O'Brien, 2007). Table 1 also shows values for internal consistency. When dependent variables were approximately normally distributed, ordinary least squares (OLS) regression was used. This was the case for the BES (skew =0.76). For the AUDIT, the value was transformed so that the skew was zero using the lnskew0 command in Stata. The resulting variable had an approximately normal distribution (Shapiro-Wilk test, $z=0.08, p=.47$ ), and OLS regression was used to assess associations between UPPS scales and the transformed AUDIT. Tobit regression models allow for the estimation of the relationship between one or more independent variables and the outcomes of interest when there is left censoring in the outcome variable. Tobit regression was used for the CUDIT, DUDIT, PCQ, and IGDS9-SF, because they had an excess of zeroes.

For each outcome we computed two models. In Model 1, we entered gender, age, and years of education in the first step and the UPPS-P scale of interest in the second step. In Model 2, we entered gender, age, and years of education in the first step and all of the UPPS-P scales in the second step. Impulsivity was considered to be significant, if the F-statistic for the second step was significant. We examined males and females together, as the relationship between UPPS-P facets and risk behaviors has been shown to be invariant across gender (Cyders, 2013; VanderVeen et al., 2016). All coefficients were derived from X-standardized variables, so that the coefficients indicate the mean increase of the dependent variable, given an increase in the UPPS-P variables of one standard deviation. We provide circular correlation graphs to illustrate the magnitude of significant coefficients in Models 1 and 2. Line width indicates the coefficients from different regression models of addictionrelated dependent variables regressed upon UPPS-P traits.
Circular graphs were created in $\mathrm{R}$ version 3.4.0 ( $\mathrm{R}$ Core Team, 2014) using the circlize package (Gu, Gu, Eils, Schlesner, \& Brors, 2014). Statistical analyses were performed using Stata 14 (StataCorp, 2015).

\section{Ethics}

The study procedures were carried out in accordance with the Declaration of Helsinki, as revised in 2008. The study was approved by the regional ethics committee ( $D e$ Videnskabsetiske Komitéer for Region Midtjylland) and participants received oral and written information about the study and gave a written consent before participating. If participants were under the age of 18 , parents also received information about the study to ensure the adolescent's consent was given under parental supervision. The questionnaires were part of a larger study including imaging and participants received DKK 1000 for their participation.

\section{RESULTS}

Participant characteristics are summarized in Table 1. The sample was predominately male, and mean age was 21.7 years. Mean scores on measures of addiction-related behaviors indicate subclinical levels: AUDIT 8.8 (SD 5.9), CUDIT-R 3.1 (SD 5.5), DUDIT 1.9 (SD 4.7), BES 7.3 (SD 4.9), PCQ 17.2 (SD 14.5), and IGDS9-SF 9.7 (SD 9.2).

Pearson's correlations between all variables are shown in Table 2. DUDIT was positively correlated with AUDIT $(0.41, p<.01)$ and CUDIT $(0.60, p<.01)$. IGDS9-SF was positively correlated with PCQ $(0.32, p<.01)$ and AUDIT was positively correlated with PCQ $(0.22, p<.05)$. 


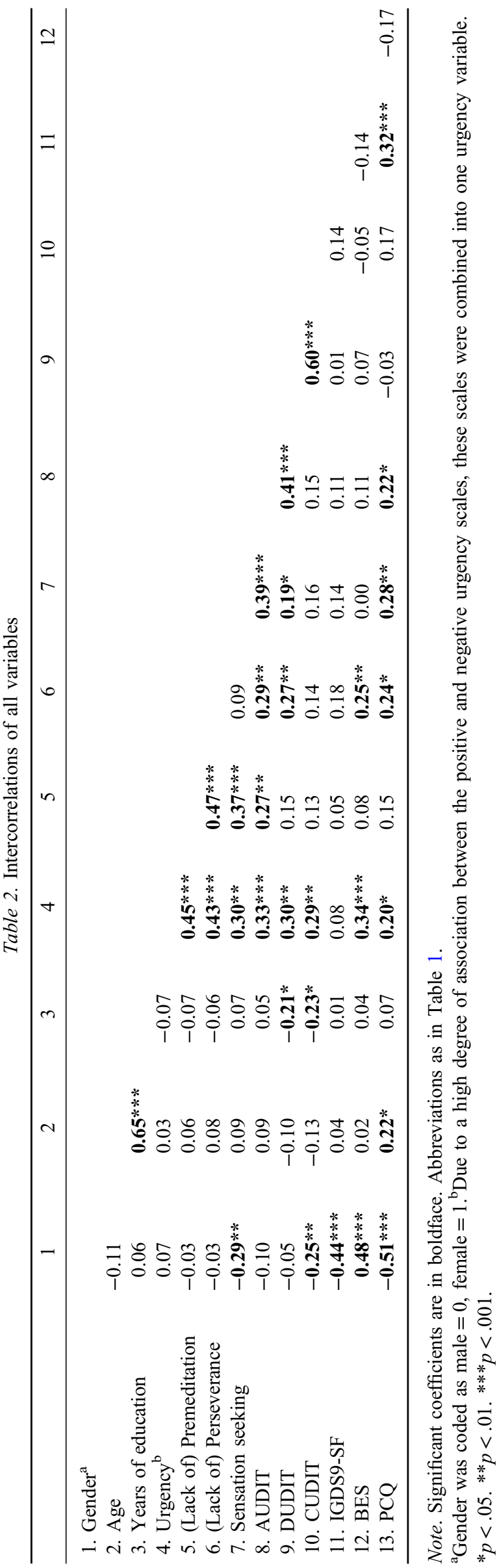

\section{Impulsivity and indicators of substance-related} addictive behaviors

The regression models are summarized in Table 3. Urgency $(p<.001)$, lack of premeditation $(p<.01)$, lack of perseverance $(p<.01)$, and sensation seeking $(p<.001)$ were positively associated with AUDIT scores after adjusting for gender, age, and education (Model 1). After adjusting for all variables (Model 2$)$, sensation seeking $(p<.001)$ and lack of perseverance $(p<.05)$ were associated with higher AUDIT-scores.

Urgency was positively associated with CUDIT scores after adjusting for gender, age, and education (Model 1, $p<.01)$. The association remained significant $(p<.01)$ after adjusting for all variables (Model 2). After entering UPPS scales (Model 2), female gender remained associated with lower scores on the CUDIT $(p<.01)$.

Urgency $(p<.01)$ and lack of perseverance $(p<.01)$ were positively associated with DUDIT scores after adjusting for gender, age, and education (Model 1). After adjusting for all variables (Model 2), lack of perseverance $(p<.05)$ remained significantly associated.

The significant coefficients from Models 1 and 2 are visualized in circular graphs in Figure 2.

\section{Impulsivity and indicators of non-substance addiction- related behaviors}

The regression models are summarized in Table 4. Urgency $(p<.001)$ and lack of perseverance $(p<.01)$ were positively associated with BES scores after adjusting for gender, age, and education (Model 1). After adjusting for all variables (Model 2), urgency $(p<.01)$ and lack of perseverance $(p<.05)$ remained significantly associated. Finally, female gender remained associated with higher scores on the BES in Model $2(p<.01)$.

Urgency $(p<.01)$ and lack of perseverance $(p<.01)$ were positively associated with PCQ scores after adjusting for gender, age and education (Model 1). After adjusting for all variables (Model 2), lack of perseverance $(p<.05)$ remained significantly associated. Furthermore, female gender remained associated with lower scores on the PCQ in Model $2(p<.001)$.

We found no significant associations between UPPS-P and problematic Internet gaming, but female gender remained associated with lower scores on IGDS9-SF in Model 2.

\section{Comparing models with versus without impulsivity traits}

We compared a baseline model consisting of age, gender, and education with a model that included these variables plus the UPPS-P variables for each of our dependent variables. Results are summarized in Table 5. For AUDIT and BES, the addition of UPPS-P variables was significantly better than the baseline model at $p<.001$. The associated R-square change was $25 \%$ for AUDIT and $15 \%$ for BES. For the CUDIT, DUDIT, and PCQ, the model was significantly better at $p<.05$. For the IGDS9-SF, the model was non-significant. 


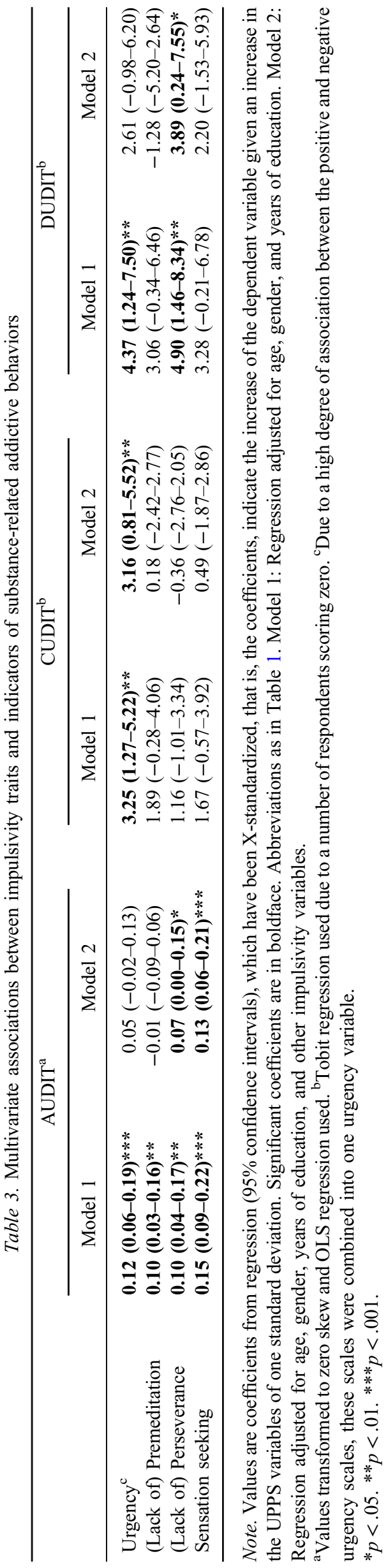

\section{DISCUSSION}

To our knowledge, this is the first study to present data on a wide range of substance and non-substance addictionrelated behaviors in relation to the UPPS-P model in the same sample, allowing for a more direct comparison of the relative contribution of UPPS-P facets to various types of addiction-related behaviors. This was possible because participants were sampled from a larger Danish cohort and stratified by externalizing problems, resulting in a broad distribution of involvement in addiction-related behaviors. Furthermore, this is the first study to examine the model in relation to problematic Internet gaming and pornography using the recently developed IGDS9-SF and PCQ. The UPPS-P model was positively associated with indicators of all addiction-related behaviors except problematic use of Internet gaming. The most important traits within the model were urgency and lack of perseverance, as one or both of these traits were associated with all the addiction-related behaviors (except Internet gaming) in the fully adjusted models.

In terms of effect sizes, the mean correlation between a UPPS-P trait and an addiction-related behavior was a modest 0.21 . For alcohol and binge eating, the models significantly improved when the UPPS-P was added with a large change in R-squared for AUDIT and a more modest, but still considerable change in R-squared for the BES, and for the two drug use disorder scales and the pornography scale, the improvement in model fit was significant at $p<.05$. Modest associations are to be expected, since impulsivity and addictive behaviors are related, but distinct constructs.

Danish youths have high consumption rates. In a recent ESPAD survey (aged 15-16 years) (Kraus, Guttormsson, et al., 2016), Denmark had the highest past month prevalence of intoxication (32\%) and binge drinking (56\%), whereas rates of past month cannabis use $(5 \%)$ were lower than most European countries. In a representative study of 15 - to 25 -year-old Danes, $10 \%$ had used cannabis the past month and $2.1 \%$ had daily use (Pedersen et al., 2015). In the ESPAD survey, Denmark had the highest prevalence rates of past month regular Internet gaming among boys (64\%) and girls (28\%) (Kraus, Guttormsson, et al., 2016). Denmark is known for its liberal and relaxed attitude toward pornography and sex, which is likely to increase consumption (Hald, 2006). A representative study of young adults found high prevalence rates of pornography consumption, for example, past month consumption (males $82.5 \%$ and females 33.6\%) (Hald, 2006). A recent review found lower rates of binge eating disorder in Nordic countries compared with other European countries, but failed to identify Danish studies (Dahlgren, Stedal, \& Wisting, 2017).

\section{Impulsivity traits and addiction-related behaviors}

In line with our hypotheses, urgency was positively associated with problematic use of alcohol (Model 1), cannabis (both models), and other drugs (Model 1). Previous studies point to an important role of urgency in problematic alcohol and cannabis use among youth (Coskunpinar et al., 2013; Stautz \& Cooper, 2013; VanderVeen et al., 2016) and cocaine dependence 

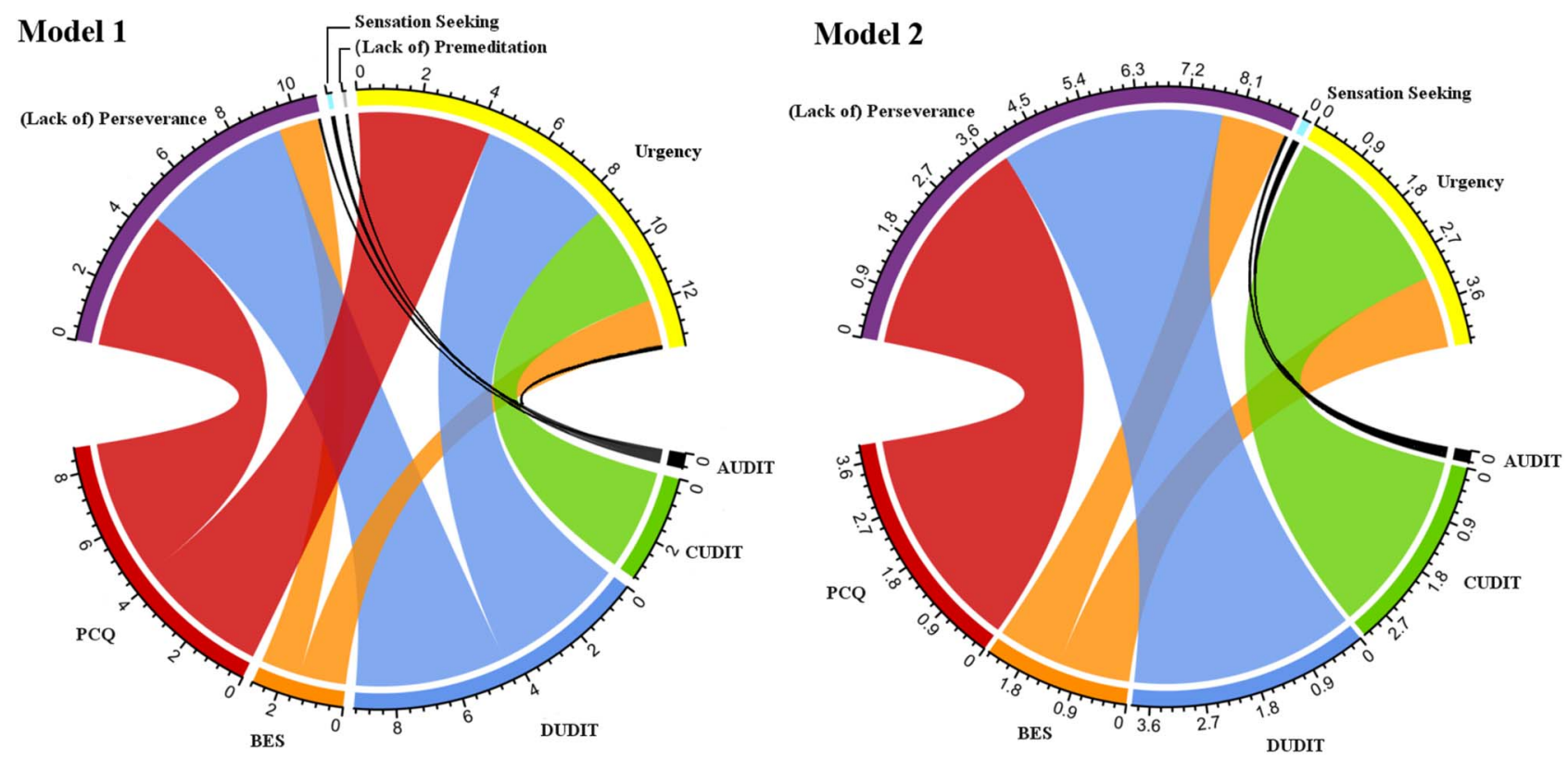

Figure 2. Circular graphs of significant associations between impulsivity traits and addiction-related behaviors. Circular graphs of the UPPS-P scales (top half) that are associated with substance and non-substance addiction-related behaviors (bottom half). Only significant estimates are shown. Line width indicates the magnitude of the individual coefficients and can be interpreted as the mean increase in an addiction-related variable with respect to an increase in the UPPS-P scale in question of one standard deviation, when age, gender, and years of education are adjusted for (Model 1) and when age, gender, years of education, and other UPPS-P scales are adjusted for (Model 2). Due to a high degree of association between the positive and negative urgency scales, these scales were combined into one urgency variable. AUDIT: Alcohol Use Disorder Identification Test; CUDIT-R: Cannabis Use Disorders Identification Test - Revised; DUDIT: Drug Use Disorder Identification Test; BES: Binge Eating Scale; PCQ: Pornography Craving Questionnaire

(Albein-Urios et al., 2012; Fernandez-Serrano et al., 2012; Torres et al., 2013). In line with our hypotheses, urgency was also positively associated with binge eating (both models) and problematic pornography use (Model 1). This resembles previous studies of binge eating in adults/young adults (Claes et al., 2015; Kelly et al., 2014; Mikheeva \& Tragesser, 2016; Murphy et al., 2014; VanderBroek-Stice et al., 2017) and a recent study linking negative urgency with addictive use of online sexual activities in males (Wery et al., 2018). The tendency to act rashly in intense positive and negative emotional states may be linked to substance and non-substance addiction-related behaviors through immediate positive and negative reinforcement, for example, through increased expectations of immediate pleasure or as a mechanism to temporarily downregulate negative emotions, despite long-term negative consequences (Cyders \& Smith, 2008; Heatherton \& Baumeister, 1991; Settles et al., 2010; Tice et al., 2001). Longitudinal studies provide some support for this idea (Anestis, Selby, \& Joiner, 2007; Pearson, Combs, Zapolslci, \& Smith, 2012; Settles, Zapolski, \& Smith, 2014; Settles et al., 2010), for example, showing that negative urgency predicts increases in the expectancy that eating alleviates negative affect, which predicts increases in binge eating (Pearson et al., 2012).

Lack of perseverance also emerged as an important trait, which was positively associated with problematic use of alcohol (Model 1), other drugs (both models), binge eating (both models), and pornography (both models). Previous studies have linked lack of perseverance with problematic alcohol use (Coskunpinar et al., 2013; Stautz \& Cooper, 2013), cocaine dependence (e.g., Verdejo-Garcia et al., 2007), and binge eating (Claes et al., 2015; Murphy et al., 2014; VanderBroek-Stice et al., 2017), but the association is generally not as strong as with urgency. To our knowledge, this is the first study to link lack of perseverance with problematic use of pornography. Lack of perseverance has been related to impairment in resistance to proactive interference (i.e., impairments in the ability to inhibit previous information that is no longer relevant) and reduced conscientiousness of ongoing tasks (Gay, Rochat, Billieux, d'Acremont, \& Van der Linden, 2008; Rochat, Billieux, Gagnon, \& Van der Linden, 2018), and may also interact with stress. A recent study showed that individuals with low levels of perseverance gambled more after experiencing a loss in a stressful situation (Canale, Rubaltelli, Vieno, Pittarello, \& Billieux, 2017). These underlying cognitive processes may help explain the reported associations between lack of perseverance and substance and nonsubstance addiction-related behaviors.

We found no associations between UPPS-P subscales and problematic Internet gaming, in line with our hypothesis and recent null findings (Deleuze et al., 2017; Irvine et al., 2013; Nuyens et al., 2016). This may suggest that factors other than trait impulsivity are linked to problematic Internet gaming behavior. Importantly, a recent study (Deleuze et al., 2017) showed that well-established risk factors for SUD and gambling disorder, including UPPS-P and other measures related to self-control, failed to discriminate between healthy gamers and gamers endorsing DSM-5 Internet gaming disorder.

A number of gender differences warrant attention. Female gender was associated with lower scores on the 
Table 5. Results of entering the UPPS model after age, gender, and years of education

\begin{tabular}{lcc}
\hline & Step statistic & $p$ value \\
\hline AUDIT $^{\mathrm{a}}$ & $F(4,102)=8.01$ & .000 \\
CUDIT $^{\mathrm{b}}$ & $F(4,102)=2.71$ & .034 \\
DUDIT $^{\mathrm{b}}$ & $F(4,102)=2.97$ & .023 \\
BES $^{\mathrm{c}}$ & $F(4,101)=6.09$ & .000 \\
PCQ $^{\mathrm{b}}$ & $F(4,102)=3.05$ & .020 \\
IGDS9-SF $^{\mathrm{b}}$ & $F(4,102)=0.79$ & .533 \\
\hline
\end{tabular}

Note. Values are $F$-tests comparing a model with gender, age, and years of education with a model that includes all UPPS scales. Abbreviations as in Table 1.

${ }^{\mathrm{a}}$ Values transformed to zero skew and OLS regression used. ${ }^{\mathrm{b}}$ Tobit regression used due to a number of respondents scoring zero. ${ }^{\mathrm{c} O L S}$ regression used.

CUDIT, PCQ, and IGD9-SF and higher scores on the BES, resembling previous studies of young people showing lower rates of females seeking treatment for cannabis use disorders (Smith, 2014), lower rates of pornography consumption (Hald, 2006) and Internet addiction (Ha \& Hwang, 2014) among females, and higher rates of binge eating disorders (Dahlgren et al., 2017). Further research with larger sample is needed to test if the same impulsive traits are expressed in different behaviors in the two genders.

Altogether, our findings stress the role of urgency and lack of perseverance in the development of substance and non-substance addiction-related behaviors (except Internet gaming). Moreover, the established associations across substance and non-substance addiction-related behaviors suggest that the increased levels of impulsivity are unlikely to result from toxic effects of substances alone.

Our findings have clinical implications by stressing the potential role of urgency and lack of perseverance in the development of substance and behavioral addictions, and hence as potential preventative therapeutic targets. Furthermore, findings point to the importance of therapeutic interventions targeting emotional regulation across these disorders, for example, interventions aimed at learning healthier strategies for coping with distress. Programs may benefit from adopting materials from psychoeducational interventions for other impulse-related disorders, such as borderline personality disorder (Zanarini, Conkey, Temes, \& Fitzmaurice, 2017) or antisocial personality disorder (Thylstrup, Schroder, \& Hesse, 2015).

Future studies are needed to replicate the non-substancerelated findings, also in clinical populations, and should include measures of emotion regulation and expectancies. Longitudinal studies with several follow-up time points are needed to tease out the direction of causality.

\section{Limitations}

The sample size was adequate to test modest $(r=.35)$, but not weaker correlations. This limitation was partially remediated by having deliberately sampled high-risk and lowrisk respondents to ensure adequate variations in terms of impulsivity. However, future studies with more power could be used to confirm and expand present findings and look into specific subgroups (e.g., gender). 
Due to the cross-sectional nature of the data, we cannot make causal inferences, that is, whether higher levels of UPPS-P traits predated higher levels of addiction-related behaviors, or the other way around. Prospective examinations are required to untangle the direction of causality.

The PCQ provides a multidimensional measure of craving, a core symptom of addictive behaviors, and hence indexes a degree of severity and problematic use. Another recent questionnaire, The short Internet Addiction Test adapted for online sexual activities (Wery, Burnay, Karila, $\&$ Billieux, 2016) may provide a broader measure of problematic use, but is restricted to online material.

The selection of youth with varying levels of EP6 was based on a representative survey of randomly selected Danish youth and hence our findings should generalize to the general population of Danish youth and to youth in countries similar to Denmark.

\section{CONCLUSIONS}

The study uniquely examined associations between the UPPS-P model and multiple addiction-related behaviors in youth with varying involvement in these behaviors. The UPPS-P model was positively associated with indicators of all addictive behaviors except problematic Internet gaming. The most important traits were urgency and lack of perseverance, as one or both of these traits were associated with all the addiction-related behaviors (except Internet gaming). Our findings highlight the potential role of urgency and lack of perseverance as predictors for the development of addictive disorders and as potential preventative therapeutic targets.

Funding sources: The project was supported by Aarhus University Research Foundation (AUFF), Assistant Professor Starting Grant - R46-A4016 (KRT, MBC, VV, and MUP), Danish Ministry for Social Affairs and the Interior - 9173-0003 (KRT, MBC, MUP, MMP, and TLK), and Medical Research Council (MRC), and Senior Clinical Fellowship - MR/P008747/1 (VV).

Authors' contribution: KRT, MBC, MUP, and VV: study concept and design and obtained funding. MUP: in charge of national survey where participants were recruited from. KRT, MBC, and MMP: data collection. MH and KRT: statistical analysis and interpretation of data. TLK: data visualization. KRT: wrote the manuscript. All authors have contributed to and approved the manuscript. They had full access to all data and take responsibility for the integrity of the data and the accuracy of the data analysis.

Conflict of interest: The author declares no conflict of interest.

Acknowledgements: The authors would like to thank the participants for taking time to travel to Aarhus and take part in the study, and Mads Jensen (Aarhus University), Nuria Donamayor (University of Cambridge), Kwangyeol Baek (University of Cambridge), and Daisy Mechelmans
(University of Cambridge) for helping with the data collection, and Center of Functionally Integrative Neuroscience/MINDLab for use of their great facilities. Furthermore, they thank Claire Mowat for helping with descriptions of the dependent variables in the manuscript. They would also like to thank Shane Kraus for the use of the PCQ.

\section{REFERENCES}

Adamson, S. J., Kay-Lambkin, F. J., Baker, A. L., Lewin, T. J., Thornton, L., Kelly, B. J., \& Sellman, J. D. (2010). An improved brief measure of cannabis misuse: The Cannabis Use Disorders Identification Test - Revised (CUDIT-R). Drug and Alcohol Dependence, 110(1-2), 137-143. doi:10.1016/j. drugalcdep.2010.02.017

Adamson, S. J., \& Sellman, J. D. (2003). A prototype screening instrument for cannabis use disorder: The Cannabis Use Disorders Identification Test (CUDIT) in an alcohol-dependent clinical sample. Drug and Alcohol Review, 22(3), 309-315. doi:10.1080/0959523031000154454

Albein-Urios, N., Martinez-Gonzalez, J. M., Lozano, O., Clark, L., \& Verdejo-Garcia, A. (2012). Comparison of impulsivity and working memory in cocaine addiction and pathological gambling: Implications for cocaine-induced neurotoxicity. Drug and Alcohol Dependence, 126(1-2), 1-6. doi:10.1016/ j.drugalcdep.2012.03.008

American Psychiatric Association. (2013). Diagnostic and statistical manual of mental disorders: DSM-V (5th ed.). Washington, DC: American Psyhiatric Association.

Amianto, F., Ottone, L., Daga, G. A., \& Fassino, S. (2015). Binge-eating disorder diagnosis and treatment: A recap in front of DSM-5. BMC Psychiatry, 15(1), 70. doi:10.1186/ s12888-015-0445-6

Anestis, M. D., Selby, E. A., \& Joiner, T. E. (2007). The role of urgency in maladaptive behaviors. Behaviour Research and Therapy, 45(12), 3018-3029. doi:10.1016/j.brat.2007.08.012

Berg, J. M., Latzman, R. D., Bliwise, N. G., \& Lilienfeld, S. O. (2015). Parsing the heterogeneity of impulsivity: A metaanalytic review of the behavioral implications of the UPPS for psychopathology. Psychological Assessment, 27(4), 1129-1146. doi:10.1037/pas0000111

Berman, A. H., Bergman, H., Palmstierna, T., \& Schlyter, F. (2005). Evaluation of the Drug Use Disorders Identification Test (DUDIT) in criminal justice and detoxification settings and in a Swedish population sample. European Addiction Research, 11(1), 22-31. doi:10.1159/000081413

Billieux, J., Lagrange, G., Van der Linden, M., Lancon, C., Adida, M., \& Jeanningros, R. (2012). Investigation of impulsivity in a sample of treatment-seeking pathological gamblers: A multidimensional perspective. Psychiatry Research, 198(2), 291-296. doi:10.1016/j.psychres.2012.01.001

Billieux, J., Schimmenti, A., Khazaal, Y., Maurage, P., \& Heeren, A. (2015). Are we overpathologizing everyday life? A tenable blueprint for behavioral addiction research. Journal of Behavioral Addictictions, 4(3), 119-123. doi:10.1556/2006.4.2015.009

Canale, N., Rubaltelli, E., Vieno, A., Pittarello, A., \& Billieux, J. (2017). Impulsivity influences betting under stress in laboratory gambling. Scientific Reports, 7(1), 1-12. doi:10.1038/s41598017-10745-9 
Canale, N., Scacchi, L., \& Griffiths, M. D. (2016). Adolescent gambling and impulsivity: Does employment during high school moderate the association? Addictive Behaviors, 60, 37-41. doi:10.1016/j.addbeh.2016.04.001

Claes, L., Islam, M. A., Fagundo, A. B., Jimenez-Murcia, S., Granero, R., Aguera, Z., Rossi, E., Menchón, J. M., \& Fernandez-Aranda, F. (2015). The relationship between nonsuicidal self-injury and the UPPS-P impulsivity facets in eating disorders and healthy controls. PLoS One, 10(5), e0126083. doi: 10.1371/journal.pone. 0126083

Colder, C. R., Scalco, M., Trucco, E. M., Read, J. P., Lengua, L. J., Wieczorek, W. F., \& Hawk, L. W. (2013). Prospective associations of internalizing and externalizing problems and their co-occurrence with early adolescent substance use. Journal of Abnormal Child Psychology, 41(4), 667-677. doi:10.1007/ s10802-012-9701-0

Coskunpinar, A., Dir, A. L., \& Cyders, M. A. (2013). Multidimensionality in impulsivity and alcohol use: A meta-analysis using the UPPS model of impulsivity. Alcoholism, Clinical and Experimental Research, 37(9), 1441-1450. doi:10.1111/ acer. 12131

Cyders, M. A. (2013). Impulsivity and the sexes: Measurement and structural invariance of the UPPS-P Impulsive Behavior Scale. Assessment, 20(1), 86-97. doi:10.1177/1073191111428762

Cyders, M. A., \& Coskunpinar, A. (2011). Measurement of constructs using self-report and behavioral lab tasks: Is there overlap in nomothetic span and construct representation for impulsivity? Clinical Psychology Review, 31(6), 965-982. doi:10.1016/j.cpr.2011.06.001

Cyders, M. A., \& Smith, G. T. (2008). Emotion-based dispositions to rash action: Positive and negative urgency. Psychological Bulletin, 134(6), 807-828. doi:10.1037/a0013341

Cyders, M. A., Smith, G. T., Spillane, N. S., Fischer, S., Annus, A. M., \& Peterson, C. (2007). Integration of impulsivity and positive mood to predict risky behavior: Development and validation of a measure of positive urgency. Psychological Assessment, 19(1), 107-118. doi:10.1037/1040-3590.19.1.107

Dahlgren, C. L., Stedal, K., \& Wisting, L. (2017). A systematic review of eating disorder prevalence in the Nordic countries: 1994-2016. Nordic Psychology, 1-19. doi:10.1080/19012276. 2017.1410071

Dalley, J. W., Everitt, B. J., \& Robbins, T. W. (2011). Impulsivity, compulsivity, and top-down cognitive control. Neuron, 69(4), 680-694. doi:10.1016/j.neuron.2011.01.020

Dalley, J. W., Fryer, T. D., Brichard, L., Robinson, E. S., Theobald, D. E., Laane, K., Peña, Y., Murphy, E. R., Shah, Y., Probst, K., Abakumova, I., Aigbirhio, F. I., Richards, H. K., Hong, Y., Baron, J. C., Everitt, B. J., \& Robbins, T. W. (2007). Nucleus accumbens D2/3 receptors predict trait impulsivity and cocaine reinforcement. Science, 315(5816), 1267-1270. doi:10.1126/science. 1137073

Deleuze, J., Nuyens, F., Rochat, L., Rothen, S., Maurage, P., \& Billieux, J. (2017). Established risk factors for addiction fail to discriminate between healthy gamers and gamers endorsing DSM-5 Internet gaming disorder. Journal of Behavioral Addictions, 6(4), 516-524. doi:10.1556/2006.6.2017.074

Duarte, C., Pinto-Gouveia, J., \& Ferreira, C. (2015). Expanding binge eating assessment: Validity and screening value of the Binge Eating Scale in women from the general population. Eating Behaviors, 18, 41-47. doi:10.1016/j.eatbeh.2015. 03.007
Edwards, A. C., Latendresse, S. J., Heron, J., Cho, S. B., Hickman, M., Lewis, G., Dick, D. M., \& Kendler, K. S. (2014). Childhood internalizing symptoms are negatively associated with early adolescent alcohol use. Alcoholism, Clinical and Experimental Research, 38(6), 1680-1688. doi:10.1111/acer.12402

Ersche, K. D., Jones, P. S., Williams, G. B., Turton, A. J., Robbins, T. W., \& Bullmore, E. T. (2012). Abnormal brain structure implicated in stimulant drug addiction. Science, 335(6068), 601-604. doi:10.1126/science.1214463

Evenden, J. L. (1999). Varieties of impulsivity. Psychopharmacology (Berl), 146(4), 348-361. doi:10.1007/PL00005481

Fernandez-Serrano, M. J., Perales, J. C., Moreno-Lopez, L., PerezGarcia, M., \& Verdejo-Garcia, A. (2012). Neuropsychological profiling of impulsivity and compulsivity in cocaine dependent individuals. Psychopharmacology (Berl), 219(2), 673-683. doi:10.1007/s00213-011-2485-z

Fischer, J. A., Najman, J. M., Williams, G. M., \& Clavarino, A. M. (2012). Childhood and adolescent psychopathology and subsequent tobacco smoking in young adults: Findings from an Australian birth cohort. Addiction, 107(9), 1669-1676. doi:10.1111/j.1360-0443.2012.03846.x

Fischer, S., \& Smith, G. T. (2008). Binge eating, problem drinking, and pathological gambling: Linking behavior to shared traits and social learning. Personality and Individual Differences, 44(4), 789-800. doi:10.1016/j.paid.2007.10.008

Garavan, H., Ross, T. J., \& Stein, E. A. (1999). Right hemispheric dominance of inhibitory control: An event-related functional MRI study. Proceedings of the National Academy of Sciences of the United States of America, 96(14), 8301-8306. doi:10.1073/pnas.96.14.8301

Gauffin, K., Vinnerljung, B., Fridell, M., Hesse, M., \& Hjern, A. (2013). Childhood socio-economic status, school failure and drug abuse: A Swedish national cohort study. Addiction, 108(8), 1441-1449. doi:10.1111/add.12169

Gay, P., Rochat, L., Billieux, J., d'Acremont, M., \& Van der Linden, M. (2008). Heterogeneous inhibition processes involved in different facets of self-reported impulsivity: Evidence from a community sample. Acta Psychologica, 129(3), 332-339. doi:10.1016/j.actpsy.2008.08.010

Gola, M., Wordecha, M., Sescousse, G., Lew-Starowicz, M., Kossowski, B., Wypych, M., Makeig, S., Potenza, M. N., \& Marchewka, A. (2017). Can pornography be addictive? An fMRI study of men seeking treatment for problematic pornography use. Neuropsychopharmacology, 42(10), 2021-2031. doi:10.1038/npp.2017.78

Gormally, J., Black, S., Daston, S., \& Rardin, D. (1982). The assessment of binge eating severity among obese persons. Addictive Behaviors, 7(1), 47-55. doi:10.1016/0306-4603(82)90024-7

Grall-Bronnec, M., Wainstein, L., Feuillet, F., Bouju, G., Rocher, B., Venisse, J. L., \& Sebille-Rivain, V. (2012). Clinical profiles as a function of level and type of impulsivity in a sample group of at-risk and pathological gamblers seeking treatment. Journal of Gambling Studies, 28(2), 239-252. doi:10.1007/s10899011-9258-9

Griffith-Lendering, M. F. H., Huijbregts, S. C. J., Mooijaart, A., Vollebergh, W. A. M., \& Swaab, H. (2011). Cannabis use and development of externalizing and internalizing behaviour problems in early adolescence: A TRAILS study. Drug and Alcohol Dependence, 116(1-3), 11-17. doi:10.1016/j. drugalcdep.2010.11.024 
Gu, Z. G., Gu, L., Eils, R., Schlesner, M., \& Brors, B. (2014). Circlize implements and enhances circular visualization in $\mathrm{R}$. Bioinformatics, 30(19), 2811-2812. doi:10.1093/bioinformatics/ btu393

Ha, Y. M., \& Hwang, W. J. (2014). Gender differences in Internet addiction associated with psychological health indicators among adolescents using a national web-based survey. International Journal of Mental Health and Addiction, 12(5), 660-669. doi:10.1007/s11469-014-9500-7

Hald, G. M. (2006). Gender differences in pornography consumption among young heterosexual Danish adults. Archives of Sexual Behavior, 35(5), 577-585. doi:10.1007/s10508-0069064-0

Heatherton, T. F., \& Baumeister, R. F. (1991). Binge eating as escape from self-awareness. Psychological Bulletin, 110(1), 86-108. doi:10.1037/0033-2909.110.1.86

Heron, J., Barker, E. D., Joinson, C., Lewis, G., Hickman, M., Munafo, M., \& Macleod, J. (2013). Childhood conduct disorder trajectories, prior risk factors and cannabis use at age 16 : Birth cohort study. Addiction, 108(12), 2129-2138. doi:10.1111/add.12268

Hildebrand, M. (2015). The psychometric properties of the Drug Use Disorders Identification Test (DUDIT): A review of recent research. Journal of Substance Abuse Treatment, 53, 52-59. doi:10.1016/j.jsat.2015.01.008

Irvine, M. A., Worbe, Y., Bolton, S., Harrison, N. A., Bullmore, E. T., \& Voon, V. (2013). Impaired decisional impulsivity in pathological videogamers. PLoS One, 8(10), e75914. doi:10.1371/journal.pone.0075914

Kaiser, A., Bonsu, J. A., Charnigo, R. J., Milich, R., \& Lynam, D. R. (2016). Impulsive personality and alcohol use: Bidirectional relations over one year. Journal of Studies on Alcohol and Drugs, 77(3), 473-482. doi:10.15288/jsad.2016.77.473

Kardefelt-Winther, D., Heeren, A., Schimmenti, A., van Rooij, A., Maurage, P., Carras, M., Edman, J., Blaszczynski, A., Khazaal, Y., \& Billieux, J. (2017). How can we conceptualize behavioural addiction without pathologizing common behaviours? Addiction, 112(10), 1709-1715. doi:10.1111/add.13763

Kelly, N. R., Cotter, E. W., \& Mazzeo, S. E. (2014). Examining the role of distress tolerance and negative urgency in binge eating behavior among women. Eating Behaviors, 15(3), 483-489. doi:10.1016/j.eatbeh.2014.06.012

Kraus, L., Guttormsson, U., Leifman, H., Arpa, S., Molinaro, S., \& Monshouwer, K. (2016). ESPAD Report 2015: Results from the European School Survey Project on alcohol and other drugs. Luxembourg: Publications Office of the European Union.

Kraus, S., \& Rosenberg, H. (2014). The Pornography Craving Questionnaire: Psychometric properties. Archives of Sexual Behavior, 43(3), 451-462. doi:10.1007/s10508-013-0229-3

Kraus, S., Voon, V., \& Potenza, M. N. (2016). Should compulsive sexual behavior be considered an addiction? Addiction, 111(12), 2097-2106. doi:10.1111/add.13297

Kuss, D. J., Griffiths, M. D., \& Pontes, H. M. (2017). DSM-5 diagnosis of Internet gaming disorder: Some ways forward in overcoming issues and concerns in the gaming studies field. Journal of Behavioral Addictions, 6(2), 133-141. doi:10.1556/ 2006.6.2017.032

Lecrubier, Y., Sheehan, D. V., Weiller, E., Amorim, P., Bonora, I., Sheehan, K. H., Janavs, J., \& Dunbar, G. C. (1997). The Mini International Neuropsychiatric Interview (MINI). A short diagnostic structured interview: Reliability and validity according to the CIDI. European Psychiatry, 12(5), 224 231. doi:10.1016/S0924-9338(97)83296-8

Lynam, D. R., Smith, G. T., Whiteside, S. P., \& Cyders, M. A. (2006). The UPPS-P: Assessing five personality pathways to impulsive behavior (Technical Report). West Lafayette, IN: Purdue University.

Meneses-Gaya, C., Zuardi, A. W., Loureiro, S. R., \& Crippa, J. A. S. (2009). Alcohol Use Disorders Identification Test (AUDIT): An updated systematic review of psychometric properties. Psychology \& Neuroscience, 2(1), 83-97. doi:10. 3922/j.psns.2009.1.12

Michalczuk, R., Bowden-Jones, H., Verdejo-Garcia, A., \& Clark, L. (2011). Impulsivity and cognitive distortions in pathological gamblers attending the UK national problem gambling clinic: A preliminary report. Psychological Medicine, 41(12), 2625 2635. doi:10.1017/S003329171100095X

Miettunen, J., Murray, G. K., Jones, P. B., Maki, P., Ebeling, H., Taanila, A., Joukamaa, M., Savolainen, J., Törmänen, S., Järvelin, M. R., Veijola, J., \& Moilanen, I. (2014). Longitudinal associations between childhood and adulthood externalizing and internalizing psychopathology and adolescent substance use. Psychological Medicine, 44(8), 1727-1738. doi: $10.1017 / \mathrm{S} 0033291713002328$

Mikheeva, O. V., \& Tragesser, S. L. (2016). Personality features, disordered eating, and alcohol use among college students: A latent profile analysis. Personality and Individual Differences, 94, 360-365. doi:10.1016/j.paid.2016. 02.004

Murphy, C. M., Stojek, M. K., \& MacKillop, J. (2014). Interrelationships among impulsive personality traits, food addiction, and body mass index. Appetite, 73, 45-50. doi:10.1016/j. appet.2013.10.008

Nuyens, F., Deleuze, J., Maurage, P., Griffiths, M. D., Kuss, D. J., \& Billieux, J. (2016). Impulsivity in multiplayer online battle arena gamers: Preliminary results on experimental and self-report measures. Journal of Behavioral Addictions, 5(2), 351-356. doi:10.1556/2006.5.2016.028

O'Brien, R. M. (2007). A caution regarding rules of thumb for variance inflation factors. Quality \& Quantity, 41(5), 673-690. doi:10.1007/s11135-006-9018-6

Pearson, C. M., Combs, J. L., Zapolslci, T. C. B., \& Smith, G. T. (2012). A longitudinal transactional risk model for early eating disorder onset. Journal of Abnormal Psychology, 121(3), 707-718. doi:10.1037/a0027567

Pedersen, M. U., Frederiksen, K. S., \& Pedersen, M. M. (2015). UngMap - en metode til identificering af sarlige belastninger, ressourcer, rusmiddelbrug/misbrug og trivsel blandt danske 15-25 årige [YouthMap - A method to identify problem severity, ressources, use/abuse of AOD and well-being among 15-25 year old Danes]. Aarhus, Denmark: Aarhus University, Centre for Alcohol and Drug Research.

Pedersen, M. U., Rømer Thomsen, K., Heradstveit, O., Skogen, J. C., Hesse, M., \& Jones, S. (in press). Externalizing behavior problems are related to substance use in adolescents across six samples from Nordic countries. European Child \& Adolescent Psychiatry.

Pedersen, M. U., Rømer Thomsen, K., Pedersen, M. M., \& Hesse, M. (2017). Mapping risk factors for substance use: Introducing the YouthMap12. Addictive Behaviors, 65, 40-50. doi:10. 1016/j.addbeh.2016.09.005 
Petry, N. M., Rehbein, F., Ko, C. H., \& O’Brien, C. P. (2015). Internet gaming disorder in the DSM-5. Current Psychiatry Reports, 17(9), 72. doi:10.1007/s11920-015-0610-0

Pontes, H. M., \& Griffiths, M. D. (2015). Measuring DSM-5 Internet gaming disorder: Development and validation of a short psychometric scale. Computers in Human Behavior, 45, 137-143. doi:10.1016/j.chb.2014.12.006

$\mathrm{R}$ Core Team (2014). $R$ : A language and environment for statistical computing. Vienna, Austria: R Foundation for Statistical Computing. Retrieved from http://www.R-project.org/

Rochat, L., Billieux, J., Gagnon, J., \& Van der Linden, M. (2018). A multifactorial and integrative approach to impulsivity in neuropsychology: Insights from the UPPS model of impulsivity. Journal of Clinical and Experimental Neuropsychology, 40(1), 45-61. doi:10.1080/13803395.2017.1313393

Rømer Thomsen, K., Joensson, M., Lou, H. C., Moller, A., Gross, J., Kringelbach, M. L., \& Changeux, J. P. (2013). Altered paralimbic interaction in behavioral addiction. Proceedings of the National Academy of Sciences of the United States of America, 110(12), 4744-4749. doi:10.1073/pnas.1302374110

Saunders, J. B., Aasland, O. G., Babor, T. F., Delafuente, J. R., \& Grant, M. (1993). Development of the Alcohol-Use Disorders Identification Test (Audit) - Who collaborative project on early detection of persons with harmful alcohol-consumption-II. Addiction, 88(6), 791-804. doi:10.1111/j.1360-0443.1993. tb02093.x

Savvidou, L. G., Fagundo, A. B., Fernandez-Aranda, F., Granero, R., Claes, L., Mallorqui-Baque, N., Verdejo-García, A., Steiger, H., Israel, M., Moragas, L., Del Pino-Gutiérrez, A., Aymamí, N., Gómez-Peña, M., Agüera, Z., Tolosa-Sola, I., La Verde, M., Aguglia, E., Menchón, J. M., \& Jimenez-Murcia, S. (2017). Is gambling disorder associated with impulsivity traits measured by the UPPS-P and is this association moderated by sex and age? Comprehensive Psychiatry, 72, 106-113. doi:10. 1016/j.comppsych.2016.10.005

Settles, R. E., Zapolski, T. C., \& Smith, G. T. (2014). Longitudinal test of a developmental model of the transition to early drinking. Journal of Abnormal Psychology, 123(1), 141-151. doi:10.1037/a0035670

Settles, R. F., Cyders, M., \& Smith, G. T. (2010). Longitudinal validation of the acquired preparedness model of drinking risk. Psychology of Addictive Behaviors, 24(2), 198-208. doi:10. 1037/a0017631

Smith, G. T., Fischer, S., Cyders, M. A., Annus, A. M., \& Spillane, N. S. (2007). On the validity and utility of discriminating among impulsivity-like traits. Assessment, 14(2), 155-170. doi:10.1177/1073191106295527

Smith, K. (2014). Gender differences in primary substance of abuse across age groups. The CBHSQ Report. Rockville, MD: Center for Behavioral Health Statistics and Quality, Substance Abuse and Mental Health Services Administration.

Sperry, S. H., Lynam, D. R., Walsh, M. A., Horton, L. E., \& Kwapil, T. R. (2016). Examining the multidimensional structure of impulsivity in daily life. Personality and Individual Differences, 94, 153-158. doi:10.1016/j.paid.2016.01.018

StataCorp. (2015). Stata statistical software: Release 14: College Station, TX: StataCorp LP.

Stautz, K., \& Cooper, A. (2013). Impulsivity-related personality traits and adolescent alcohol use: A meta-analytic review. Clinical Psychology Review, 33(4), 574-592. doi:10.1016/j. cpr.2013.03.003
Thylstrup, B., Schroder, S., \& Hesse, M. (2015). Psycho-education for substance use and antisocial personality disorder: A randomized trial. BMC Psychiatry, 15(1), 283. doi:10.1186/ s12888-015-0661-0

Tice, D. M., Bratslavsky, E., \& Baumeister, R. F. (2001). Emotional distress regulation takes precedence over impulse control: If you feel bad, do it! Journal of Personality and Social Psychology, 80(1), 53-67. doi:10.1037/0022-3514.80.1.53

Torres, A., Catena, A., Megias, A., Maldonado, A., Candido, A., Verdejo-Garcia, A., \& Perales, J. C. (2013). Emotional and non-emotional pathways to impulsive behavior and addiction. Frontiers in Human Neuroscience, 7, 43. doi:10.3389/fnhum. 2013.00043

VanderBroek-Stice, L., Stojek, M. K., Beach, S. R., van Dellen, M. R., \& MacKillop, J. (2017). Multidimensional assessment of impulsivity in relation to obesity and food addiction. Appetite, 112, 59-68. doi:10.1016/j.appet.2017.01.009

VanderVeen, J. D., Hershberger, A. R., \& Cyders, M. A. (2016). UPPS-P model impulsivity and marijuana use behaviors in adolescents: A meta-analysis. Drug and Alcohol Dependence, 168, 181-190. doi:10.1016/j.drugalcdep.2016.09.016

Verdejo-Garcia, A., Bechara, A., Recknor, E. C., \& Perez-Garcia, M. (2007). Negative emotion-driven impulsivity predicts substance dependence problems. Drug and Alcohol Dependence, 91(2-3), 213-219. doi:10.1016/j.drugalcdep.2007.05.025

Verdejo-Garcia, A., Lozano, O., Moya, M., Alcazar, M. A., \& Perez-Garcia, M. (2010). Psychometric properties of a Spanish version of the UPPS-P Impulsive Behavior Scale: Reliability, validity and association with trait and cognitive impulsivity. Journal of Personality Assessment, 92(1), 70-77. doi:10.1080/ 00223890903382369

Voluse, A. C., Gioia, C. J., Sobell, L. C., Dum, M., Sobell, M. B., \& Simco, E. R. (2012). Psychometric properties of the Drug Use Disorders Identification Test (DUDIT) with substance abusers in outpatient and residential treatment. Addictive Behaviors, 37(1), 36-41. doi:10.1016/j.addbeh.2011.07.030

Voon, V., \& Dalley, J. W. (2016). Translatable and backtranslatable measurement of impulsivity and compulsivity: Convergent and divergent processes. Translational Neuropsychopharmacology, 28, 53-91. doi:10.1007/7854_2015_5013

Voon, V., Irvine, M. A., Derbyshire, K., Worbe, Y., Lange, I., Abbott, S., Morein-Zamir, S., Dudley, R., Caprioli, D., Harrison, N. A., Wood, J., Dalley, J. W., Bullmore, E. T., Grant, J. E., \& Robbins, T. W. (2014). Measuring "waiting" impulsivity in substance addictions and binge eating disorder in a novel analogue of rodent serial reaction time task. Biological Psychiatry, 75(2), 148-155. doi:10.1016/j.biopsych. 2013.05.013

Voon, V., Mole, T. B., Banca, P., Porter, L., Morris, L., Mitchell, S., Lapa, T. R., Karr, J., Harrison, N. A., Potenza, M. N., \& Irvine, M. (2014). Neural correlates of sexual cue reactivity in individuals with and without compulsive sexual behaviours. PLoS One, 9(7), e102419. doi:10.1371/journal. pone.0102419

Wery, A., Burnay, J., Karila, L., \& Billieux, J. (2016). The short French Internet Addiction Test adapted to online sexual activities: Validation and links with online sexual preferences and addiction symptoms. The Journal of Sex Research, 53(6), 701-710. doi:10.1080/00224499.2015.1051213

Wery, A., Deleuze, J., Canale, N., \& Billieux, J. (2018). Emotionally laden impulsivity interacts with affect in predicting addictive use 
of online sexual activity in men. Comprehensive Psychiatry, 80 , 192-201. doi:10.1016/j.comppsych.2017.10.004

Whiteside, S. P., \& Lynam, D. R. (2001). The five factor model and impulsivity: Using a structural model of personality to understand impulsivity. Personality and Individual Differences, 30(4), 669-689. doi:10.1016/S0191-8869(00)00064-7

Whiteside, S. P., \& Lynam, D. R. (2003). Understanding the role of impulsivity and externalizing psychopathology in alcohol abuse: Application of the UPPS Impulsive Behavior Scale. Experimental and Clinical Psychopharmacology, 11(3), 210-217. doi:10.1037/1064-1297.11.3.210
Young, S. E., Corley, R. P., Stallings, M. C., Rhee, S. H., Crowley, T. J., \& Hewitt, J. K. (2002). Substance use, abuse and dependence in adolescence: Prevalence, symptom profiles and correlates. Drug and Alcohol Dependence, 68(3), 309-322. doi:10.1016/S0376-8716(02)00225-9

Zanarini, M. C., Conkey, L. C., Temes, C. M., \& Fitzmaurice, G. M. (2017). Randomized controlled trial of web-based psychoeducation for women with borderline personality disorder. The Journal of Clinical Psychiatry. Advance online publication. doi:10.4088/JCP.16m11153 